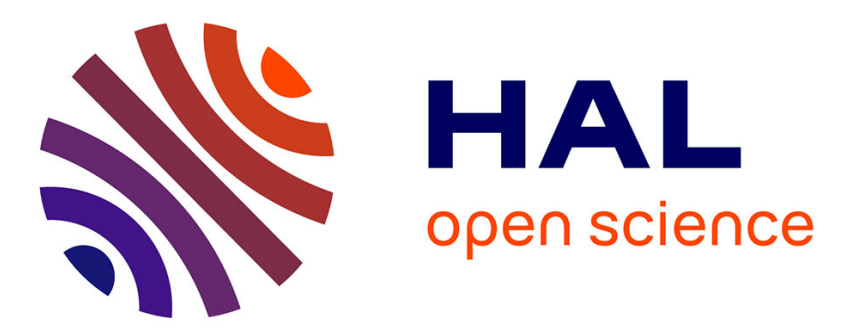

\title{
Application of drug discovery software to the identification of heparin-binding sites on protein surfaces: a computational survey of the 4-helix cytokines.
}

\author{
Barbara Mulloy, Mark J. Forster
}

\section{To cite this version:}

Barbara Mulloy, Mark J. Forster. Application of drug discovery software to the identification of heparin-binding sites on protein surfaces: a computational survey of the 4-helix cytokines.. Molecular Simulation, 2008, 34 (04), pp.481-489. 10.1080/08927020701784754 . hal-00515025

\section{HAL Id: hal-00515025 \\ https://hal.science/hal-00515025}

Submitted on 4 Sep 2010

HAL is a multi-disciplinary open access archive for the deposit and dissemination of scientific research documents, whether they are published or not. The documents may come from teaching and research institutions in France or abroad, or from public or private research centers.
L'archive ouverte pluridisciplinaire HAL, est destinée au dépôt et à la diffusion de documents scientifiques de niveau recherche, publiés ou non, émanant des établissements d'enseignement et de recherche français ou étrangers, des laboratoires publics ou privés. 


\section{Molecular Simulation}

\section{Application of drug discovery software to the identification of heparin-binding sites on protein surfaces: a computational survey of the 4-helix cytokines.}

\begin{tabular}{|r|l|}
\hline Journal: & Molecular Simulation/Journal of Experimental Nanoscience \\
\hline Manuscript ID: & GMOS-2007-0095.R2 \\
\hline Journal: & Molecular Simulation \\
\hline Date Submitted by the \\
Author: & $29-$ Oct-2007 \\
\hline Complete List of Authors: & $\begin{array}{l}\text { Mulloy, Barbara; NIBSC, LMS } \\
\text { Forster, Mark; Syngenta, R\&D IS }\end{array}$ \\
\hline Keywords: & heparin, heparan sulfate, cytokine, drug discovery, docking \\
\hline
\end{tabular}

\section{SCHOLARONE Manuscripts}




\section{Page 1 of 34}

1

Application of drug discovery software to the identification of heparin-binding sites on protein surfaces: a computational survey of the 4-helix cytokines.

Barbara Mulloy ${ }^{1}$ and Mark J. Forster ${ }^{2}$

National Institute for Biological Standards and Control, Blanche Lane, South Mimms, Potters Bar, Hertfordshire EN6 3QG, UK.

${ }^{1}$ Author for correspondence

${ }^{2}$ Current address: Syngenta R\&D IS, Jealotts Hill International Research Centre, Bracknell, Berkshire RG42 6EY, UK.

Running title: Heparin-binding sites

Keywords: heparin, heparan sulfate, cytokine, drug discovery, docking.

\section{1}




\title{
| Abstract
}

Formatted: Font: Bold

\begin{abstract}
Heparin, best known as a potent anticoagulant, also interacts with many other proteins for which the natural ligand is heparan sulfate. The hope that heparan sulfate would display specific sequences which would bind selectively to each of these proteins has not been fulfilled, but this may be at least in part due to the relationship between heparan sulfate sequence and three-dimensional structure. The example of FGF-1 is used to demonstrate that many different sequences can give rise to the three-dimensional patterns of charge which form binding motifs for proteins. Partly because of this redundancy in sequenceto-structure relationship, the application of conventional high-throughput drug discovery methods for the development of heparin or heparan based therapeutic agents is not yet practicable. However, it is possible to adapt systematic docking calculations to work in a moderately high throughput manner to screen protein structures from the PDB for predicted heparin binding sites. A survey of protein structures in the SCOP superfamily of 4-helical cytokines is presented.
\end{abstract}


1

2

3

4

5

6

7

8

9

\section{Introduction}

The process of drug discovery may be generally defined as "the decision making process in the pharmaceutical industry by which compounds are identified and selected for clinical trial"[1]. Within the last twenty years the phrase has come increasingly to refer to a set of systematic, high throughput techniques for the screening of small molecule drug candidates. Such techniques include both experimental and theoretical screening methods, and there are many possible strategies for combining the two to yield agents which will interact effectively and selectively with a particular protein target, often an enzyme or a receptor.

It is clear that not all useful drugs can be found in this way: heparin is a case in point. This highly heterogeneous polysaccharide (Fig. 1), because of its variable patterns of sulfation and its domain structure, is capable of containing many different sequence motifs. It is a particularly highly sulfated example of the class of glycosaminoglycans (GAGs) known as heparan sulfate [2], and is found in mast cell granules, where it is essential for the correct storage of proteases [3, 4]. Heparan sulfate (HS) is present, as the glycan side-chain of several proteoglycans, on the surfaces of most cells_[2] and in the extracellular matrix [5], where it interacts with, and modulates the actions of, many of the cytokines, chemokines, growth factors, and other proteins which exert their effects in inflammation [6], reproduction [7], the immune system, and embryonic differentiation and development [8]. 


\section{Sequence and structure in heparin and heparan sulfate}

The most intensively studied and best understood sequence of monosaccharide residues in heparin is an unusual pentasaccharide which is the minimum requirement for high affinity to antithrombin. It is this sequence which accounts for the high anticoagulant potency of heparin, and hence its use as an antithrombotic agent; the essential pentasaccharide has been prepared synthetically and is itself used as a drug [9]. When it became clear that heparin, as a model compound for heparan sulfate, was capable of physiologically important interactions with other classes of protein, such as the fibroblast growth factors [10], the example of the antithrombin-binding sequence led to a search for other, equally specific sequences in either heparin or heparan sulfate which would confer particular affinity for any given binding partner. This search for specificity of a high order has on the whole been unsuccessful, and a recent study of structures which are capable of potentiating fibroblast growth factor (FGF)-mediated cell growth has concluded that heparan sulfate fine structure may be less influential than has previously been supposed [11]. However, evidence from studies of model organisms has shown that sulfation at specific positions of heparan sulfate is important for some aspects of correct embryonic development [12], and it has also been demonstrated, in a quite separate area, that recognition of sulfation patterns of polysaccharides by proteins is both possible and physiologically significant $[13,14]$.

Heparan sulfate is often represented, and imagined, in terms of sequences, rather than three-dimensional structures [15]. The crystal structure of FGF-1 (2axm.pdb) complexed with a heparin oligosaccharide (Fig. 2)[16] shows clearly that the pattern of sulfate 
1

2

3

4

5

6

7

8

9

10

groups interacting with the protein can be formed in two ways, involving clusters of sulfate and carboxylate substituents on either side of the polysaccharide chain. Two separate molecules of FGF-1, aligned in opposite directions along the heparin chain, each interact with a cluster of three sulfates, part of a second cluster, and the carboxylate between the two clusters. The charge-based interactions, between the acidic substituents on the polysaccharide and basic residues on the surface of the protein, usually dominate the interface, and the detailed nature of the sugar backbone carrying the substituents is much less important, so long as it presents the substituents in an appropriate threedimensional pattern. This "pseudo-symmetry", in which the underlying asymmetry of the sugar backbone is hidden by the almost symmetrical arrangement of bulky and highly charged substituents, is a complicating factor in the interpretation of heparan sulfate sequence requirements for affinity with different proteins. Another such factor is the finding that, for most interactions between heparin and proteins, substitution with additional sulfate groups does not decrease affinity. Bearing in mind both factors together, a simplistic calculation indicates 31 different pentasaccharide sequences (starting and ending with glucosamine) which will contain a single FGF-1 binding motif Leaving the motif on one side of the molecule (Fig. 2) undisturbed, and assuming that any or all of the four remaining sulfated positions may or may not be occupied, $16\left(2^{4}\right)$ different possible compounds can be defined. Repeating this exercise for the second side gives 31 possible sequences in all (not counting the fully sulfated compound twice)._Such a sequence is more likely to occur in highly sulphated regions of the polysaccharide. Potentiation of growth factor activity is more complex than simple affinity for the growth factor itself, and it is clear that the requirements for functional interaction with the growth 
factor/receptor complex are not the same as for the growth factor alone [17]; still, the search for a 3-D pattern is more likely to be successful than for a specific sequence.

\title{
Drug discovery techniques
}

The use of three-dimensional models in drug design is not a new concept [18]. Molecular modelling techniques, in particular those in which a small molecule is docked into its binding site, are frequently used in the design of new drugs.

A conventional application of theoretical techniques to the process of designing a new drug would be to take a particular protein, for example an enzyme, and to look at the detailed experimental structure of a complex between the protein and its ligand, for example a substrate or inhibitor. On the basis of the structural details of the ligand and its binding site, new compounds may be proposed, perhaps with a view to increasing the affinity of an inhibitor. The compounds can be screened by molecular modelling, using the technique known as docking calculations, which explore many mutual orientations of protein and ligand to find out how best to accommodate the ligand in the binding site. Compounds with the best affinity for the protein will produce theoretical complexes with favourably low interaction energies. For glycosaminoglycan-protein interactions this course of action is not yet practicable. For one thing, the detailed modelling of GAG ligands with proteins is technically challenging [19], and secondly, the definition of a binding motif in heparin or heparan sulfate in terms of its sequence is problematic, as described above. In addition, heparin and its fragments do not bind tightly to deep clefts in the protein surface, but to superficial sites, and the complexes are formed largely by electrostatic interactions. The molecular modelling of glycosaminoglycan sequences has therefore not yet reached the stage at which docking different sequences to one particular

\author{
6
}


protein is useful; but the reverse process, in which a generic heparin model ligand is used to find GAG binding sites on the surfaces of many proteins, is possible. Several groups have developed protocols for a systematic search of the entire surface of a protein to find the best heparin binding site [20-22]. We have used a combination of predictive docking with experimental studies in the successful identification of several heparin binding sites [23-25].

\section{Docking protocol for identification of heparin binding sites on protein surfaces}

Our docking strategy was developed with the aim of discovering potential heparin-

binding sites on protein surfaces, for use both in the illustration and rationalisation of

experimental results such as NMR titrations [23] or the design of site-directed

mutagenesis experiments [25]. As it is not necessarily the case that heparin structures

will bind to proteins in a single, defined orientation (see for example the case of FGF-1

described in the previous section), no emphasis was placed on the detailed prediction of

the geometry of the complexes, or accurate calculation of the interaction energy. Rather

than the conventional use of docking techniques, in which the geometry of a small ligand

molecule in a known high-affinity binding site is optimised, we used a simple protocol to

screen the entire surface of a small protein for clusters of basic residues which offer

$\underline{\text { suitable shape and charge profiles complementary to the pattern of acidic substituents }}$

along the heparin chain.

Docking of several heparin oligosaccharide ligand models to protein structures was

performed as previously described [26] using Autodock, version 2.4 [27], with partial

charges for protein atoms taken from the AutoDock version of the AMBER force field.

Co-ordinates for the heparin oligosaccharide ligands were derived from the NMR

Deleted: An $84 \AA$ grid with $7 \AA$ spacing was used, to accommodate the full surface of a small protein. 
structure for the predominant repeating disaccharide of heparin 1hpn.pdb [28] with partial atomic charges from ab initio calculations using the Jaguar program (Schrodinger Inc,

Portland, Oregon, USA) on 1-OMe 4-OMe substituted monosaccharides. Two

pentasaccharide ligands were used, each with glucosamine at both reducing and non-

reducing termini. For one of these, the two iduronate residues were both in the ${ }^{1} \mathrm{C}_{4}$

conformation, and for the other they were both in the ${ }^{2} \mathrm{~S}_{0}$ conformation; in heparin both

these forms are in equilibrium. All the exocyclic bonds in these pentasaccharide models

were regarded as rotatable with the exception of the glycosidic linkages. Some

calculations were also performed using a completely rigid endecasaccharide ligand

model.

Docking was typically performed on a grid of 120x120x120 points, with the addition of a central grid point. The grid was centred on the mean of the coordinates of the protein.

Grid spacing was 0.7 Angstroms, leading to a grid of $84 \times 84 \times 84$ Angstroms. This

determines the largest protein that can be studied by this protocol. Separate grids of

VDW interaction energy are then calculated for each atom type in the ligand $(\mathrm{C}, \mathrm{N}, \mathrm{H}, \mathrm{S}, \mathrm{O})$

and an electrostatic interaction energy grid is computed for a single electron charge.

These grids are used during the docking process to rapidly calculate the interaction

energy of the ligand with the protein. This is achieved by finding the grid points

surrounding each ligand atom and using an interpolation procedure to find the energy

contribution at the current coordinates. The energies are them summed over all atoms in

the ligand and the torsion energy terms added to the VDW and electrostatic energies.

During the docking procedure the position, orientation and allowed torsion angles of the

ligand structure are optimised by a monte carlo simulated annealing procedure. Initial
Deleted: No attempt was made to simulate solution conditions; a constant dielectric of 1.0 was used.TI

The protocol was validated by predicting the position of heparin binding sites for FGF-2; agreement between the predicted heparin binding site and experimental data from the crystal structures of FGF2/heparin complexes was excellent

Formatted: Font: 12 pt, Complex Script Font: 12 pt
Formatted: Font: $12 \mathrm{pt}$, Complex Script Font: 12 pt 


\section{Use of docking calculations to screen the structure database for heparin-binding proteins}

The docking protocol can readily be performed on a medium-high throughput basis, so that the possibility arises of a systematic survey of proteins with known threedimensional structures, in order to supplement the limited number of experimentally determined heparin-protein complexes [30]. There are over 41,000 structures in the PDB, however, so an initial survey of a subset of solved protein structures is desirable. In the SCOP (Structural Classification of Proteins) [31] system (http://scop.mrclmb.cam.ac.uk/scop/), members of the Superfamily of 4-helical cytokines (in the Class of 9 
all-alpha proteins) form a suitable group (Fig. 3). They are small proteins, related in functional terms as well as by structure, and all performing their biological functions outside the cell, so that their environment is rich in glycosaminoglycans.

We have performed semi-automated docking calculations using the program Autodock, as previously described [26], with co-ordinates for the heparin-based oligosaccharide ligands taken from the PDB file $1 \mathrm{hpn} . \mathrm{pdb}$ [28] and co-ordinates for proteins derived from PDB files (http://www.rcsb.org/pdb/) corresponding to experimentally determined structures in the SCOP families of long- and short-chain 4-helical cytokines, and the | interferon/interleukin 10 (IL-10) group. Only the structures of human cytokines were chosen. For all the proteins except for interleukin-5 (IL-5), interleukin-6 (IL-6), and interleukin-10 one monomer of the protein was used for docking; a single chain was edited from the pdb file where that file contained more than one chain. No attempts were made to replace missing co-ordinates in the pdb files by molecular modelling. Heparinprotein complexes calculated to have intermolecular interaction energies of less than $1000 \mathrm{kcal} / \mathrm{mol}$ were regarded as predictions of capacity to bind heparin; those with interaction energies of more than 0 were regarded as predicting no capacity to bind heparin. The energy units of the Autodock function are usually given as $\mathrm{kcal} / \mathrm{mol}$; the high figures in the Tables are a consequence of the high weighting given to electrostatic terms in the forcefield by using a unit dielectric constant. Values given should be understood as the results of a ranking function with no significance in absolute terms. Coordinates were visualised and figures prepared using the programs InsightII and Weblab Viewer (Accelrys). 


\section{Long-chain cytokines}

Docking calculations were possible for seven members of this family, listed in Table 1, out of a total of 9. Interleukin-12 was omitted, as inspection of the crystal structure (1f45.pdb) showed that the 4-helical bundle is a minor part of this structure, which also includes a second subunit made up of three IgG domains [32], and the co-ordinates for Oncostatin M (1evs.pdb) were too incomplete to give anything other than an artefactual result. Four members of this group are strongly predicted to bind to heparin: Leukaemia inhibitory factor (LIF), IL-6, erythropoietin (EPO) and thrombopoietin (TPO). Heparin is known to interact with IL-6, and a site involving the A and D helices has been proposed [33], which is entirely consistent with our predictions. This face of the bundle is closely involved with receptor interactions, and the proposed heparin binding site lies close to, though not overlapping, the areas of IL-6 which interact with both its receptors; IL-6R and gp130. Though it is possible to imagine heparin occupying the site at the same time as either of the two receptors, simple steric factors prevent heparin binding to the complete signaling complex of IL-6 with both receptors. Leukaemia inhibitory factor (LIF) has not so far been identified as a heparin-binding protein, but the docking results are highly indicative that an interaction is possible, though in contrast with IL-6 the proposed heparin binding site lies along the length of helix A, extensively overlapping the gp130 binding site. Ciliary neurotrophic factor (CNTF) is involved in neuronal cell growth and survival; like IL-6 and LIF, it has gp130 as part of its receptor complex. CNTF also shares the LIF receptor, though unlike LIF, CNTF requires a specific, non- 
signalling receptor in addition [34]. Unlike IL-6 and LIF, CNTF has no plausible heparin binding site.

Both EPO and TPO are classified as long-chain cytokines with short-chain topology.

Although neither cytokine is recognised as a heparin binding protein, the docking calculations indicate that a well-formed heparin binding site is present on both. The crystal structure of the complex between EPO and two receptor molecules [35] clearly displays the same linear pattern of basic residues along helix D, which passes through the centre of one of the EPO receptor binding regions (Fig. 4).

For the remaining long-chain cytokines, the results are as would be expected for a chance patch of basic residues on the protein surface rather than a functional heparin binding site, though heparin has been reported to interact with some of them (G-CSF [36] and somatotropin (human growth hormone: hGH) [37]).

\section{Short-chain cytokines}

Eight structures are listed in Table 2: a ninth, macrophage colony-stimulating factor, was omitted as co-ordinates (1hmc.pdb) were incomplete. Strongly positive predictions of heparin binding were made for interleukins 2, 4 and 13 (IL-2, IL-4 and IL-13), and (less strongly) for interleukin 3 (IL-3); a positive prediction is also made for the intertwined dimer IL-5. Interactions have been found experimentally between heparin and IL-2 [38], IL-3 [39], IL-4[40], and IL-5 [41], but not reported so far for IL-13. Overlaid complexes for IL-2, IL-3, IL-4 and IL-13 are shown in Fig. 5.

The NMR structure of IL-3 (1jli.pdb) has as many as 13 altered amino acids. The predicted heparin binding site involves none of these, but the prediction should still be 
1

2

3

4

5

6

7

8

9

10

regarded with caution. Like GM-CSF, IL-3 is adsorbed by heparan sulfate [39], but no detailed structural description of the interaction is available.

GM-CSF cannot be confidently predicted to bind heparin on the basis of the docking calculations. However, pH-dependent interaction between GM-CSF and heparin has been described, and three histidine residues identified as important for binding [42]. In the crystal structures, these residues are not exposed, but it is possible this is not the case for the solution structure at low $\mathrm{pH}$.

The Flt3-ligand (Flt-31) and stem cell factor (SCF) have overlapping biological functions and share a receptor type [43], but are dissimilar in their predicted behaviour towards heparin. While it is possible that Flt-31 may bind heparin, the prediction for SCF is strongly negative. The crystal structures of both Flt-3 ligand (1ete.pdb) and SCF (1exz.pdb) contain co-ordinated metal ions, which are not taken into account in our docking protocol. While for the acidic protein SCF this is unlikely to introduce any heparin binding capacity, it is conceivable that the presence of zinc might influence heparin binding to Flt-3.

\section{Interferons/interleukin 10 family}

Members of this group have an extra short helix in one of the crossover connections; their heparin-binding predictions are listed in Table 3. Interferons $\alpha-2 \mathrm{~A}$ (1itf.pdb), $\beta$ (1au1.pdb) and $\gamma$ (1eku.pdb) were considered, and here the results of the docking calculations meet a common problem. A clear prediction was obtained only for interferon- $\beta$, which has a strong potential binding site extending over helices A and D; a less clear prediction places a possible heparin binding site in the same area for interferon$\alpha 2 \mathrm{~A}$. For interferon- $\gamma$, post-calculation review of relevant literature indicated that 
prediction of a heparin binding site by this method is not valid, as the heparin binding site is known to be situated on an unstructured C-terminal tail [44]. It is not wise to place reliance on a prediction of this kind for the globular domain of a protein with $\mathrm{N}$ - or Cterminal unstructured sequences, without careful inspection of the unstructured sequences for concentrations of basic amino acids. Modelling of the complex would require an exhaustive conformation sampling scheme, followed by docking on each conformer generated. For an unstructured region of more than a few residues this procedure is not practicable.

Three interleukin structures also fall into this family; those for IL-10, interleukin 19 (IL19) and interleukin 22 (IL-22). IL-10 is an intertwined dimer, whereas IL-19 and IL-22 are not. Predictions for both IL-19 and IL-22 are not clear; heparin may bind to IL-22 by the helix-A/helix-D face, and to IL-19 by the C-D loop and residues at the C-terminus.

Heparin is strongly predicted to bind to IL-10, interacting with both bundles in the dimer, and heparin-IL/10 binding has been observed experimentally [45].

\section{Discussion}

A structural comparison among short-chain helical cytokines [46] has pointed out that, though these compounds are structurally and functionally related, their amino acid sequences are not strongly similar. This is true of the 4-helical cytokines in general, but in spite of poor sequence conservation, they are considered a monophyletic group, arising at some point in the distant past from a single ancestral gene [47]. Their receptors are however closely related, and shared subunits are common: for example the gp130 | receptor subunit shared by several of the long-chain cytokines (such as Il-6 and LIF) and 
1

2

| the common gamma receptor subunit shared by several short-chain cytokines. There are clearly elements of surface character in common between cytokines which share receptors, and it is reasonable to ask whether other surface features, such as heparin binding sites, are shared. However, the results of this brief survey do not indicate that the capacity to bind heparin, or the site at which heparin might bind, is conserved between the 4-helical cytokines, as is shown by the comparison of the four heparin binding sites of IL-2, IL-3, IL-4 and IL-13 illustrated in Fig. 5. The heparin binding site for IL-2 is constructed from loops [38], whereas those for the other three interleukins lie across helices $\mathrm{A}$ and $\mathrm{D}$, or $\mathrm{A}$ and $\mathrm{C}$.

This study was undertaken in part to investigate the feasibility of high-throughput screening of structures in the PDB for the presence of heparin-binding sites, in order to add to the limited number of such sites so far defined by crystallized complexes. Several problems arise for this type of exercise. First, there are entries in the PDB which are incomplete, and missing residues in loop or terminal unstructured regions may cause a heparin-binding protein to be missed. Secondly, it is not always clear which oligomeric form of the protein is most appropriate for the docking exercise. Other considerations include glycosylation and other post-translational modifications, which are not always clear in the PDB structure. However, it is relatively quick and simple to generate results from our protocol. Several of the predictions made will be investigated experimentally. Detailed analysis of the predicted binding sites has been avoided as being premature in the absence of experimental data. Though these molecular modelling exercises offer no 
more than informed predictions, they are in agreement with all the experimental data so far in failing to identify any single amino acid sequence motif or feature of secondary structure common to all heparin binding sites [15, 26, 48]. The significance and function (if any) of the capacity of cytokines to bind heparin or heparan sulfate cannot be generalised; each case requires separate investigation. However, it seems unlikely that heparan sulfate acts as a co-receptor for these cytokines by analogy with the fibroblast growth factors, as so many of the predicted heparin binding sites overlap receptor binding sites. An ability to bind to glycosaminoglycans in the extracellular matrix may reasonably be expected to affect the diffusion of cytokines, and it may be in the location, rather than the signaling, of cytokines that heparan sulfate plays its part in their action. 
Table 1 Prediction of heparin binding to long-chain cytokines:

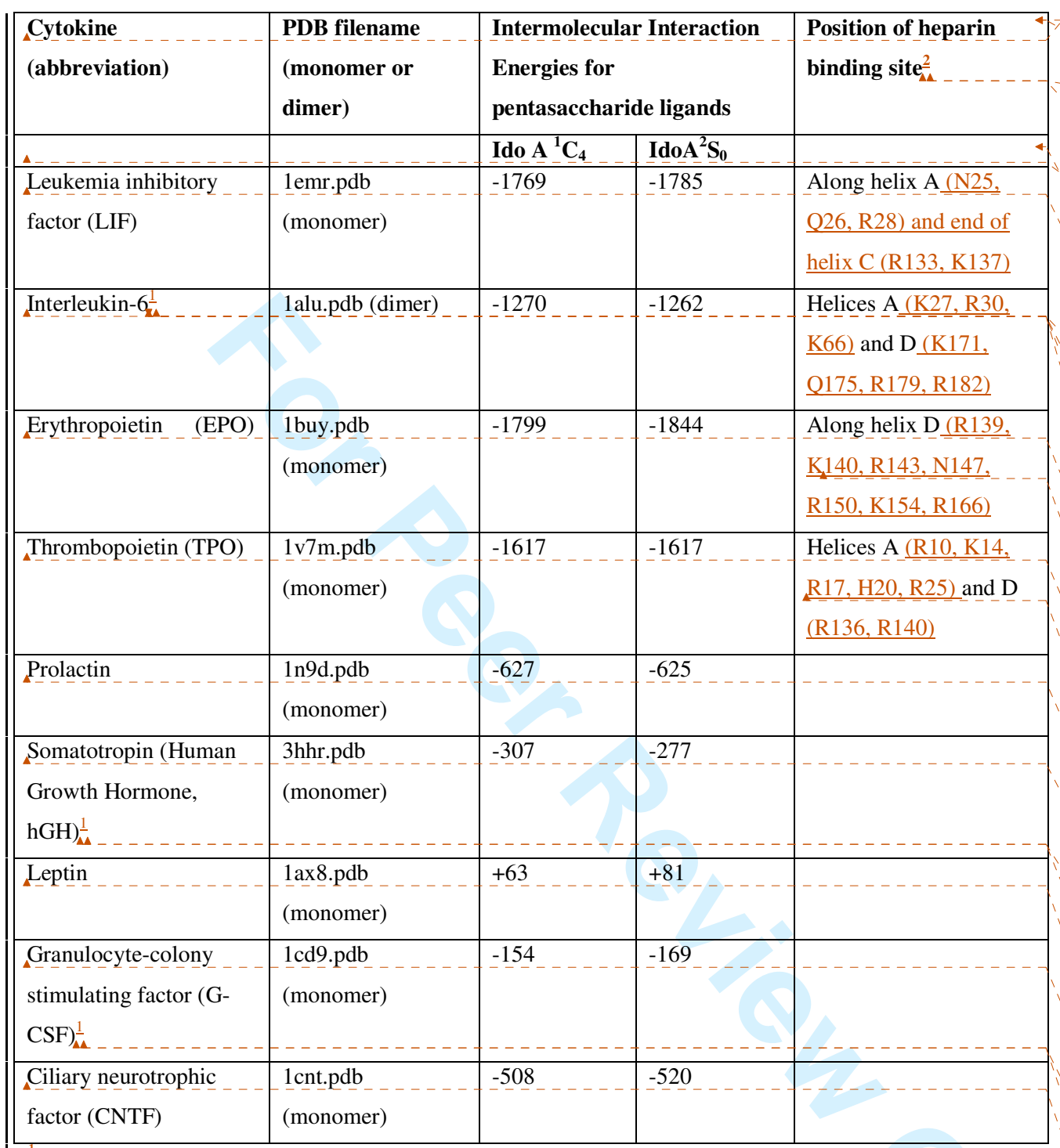

${ }_{2}^{1}$ Reported to interact with heparin: see text

${ }^{2}$ Residues containing atoms within $3.5 \AA$ of ligand in the 5 lowest energy complexes,

Table 2 Prediction of heparin binding to short-chain cytokines:
Formatted: Font: $10 \mathrm{pt}$, Complex Script Font: $10 \mathrm{pt}$

Formatted Table

Formatted: Line spacing: 1.5 lines

Formatted: Font: $10 \mathrm{pt}$, Complex Script Font: $10 \mathrm{pt}$, Superscript

Formatted: Font: 10 pt, Complex Script Font: $10 \mathrm{pt}$

Formatted: Font: $10 \mathrm{pt}$, Complex Script Font: $10 \mathrm{pt}$

Formatted: Line spacing: Multiple $1.15 \mathrm{li}$

Formatted: Font: $10 \mathrm{pt}$, Complex

Script Font: $10 \mathrm{pt}$

Formatted: Font: $10 \mathrm{pt}$, Complex Script Font: $10 \mathrm{pt}$

Deleted: "

Formatted: Font: $10 \mathrm{pt}$, Complex Script Font: 10 pt, Superscript

Formatted: Font: $10 \mathrm{pt}$, Complex Script Font: $10 \mathrm{pt}$

Formatted: Font: $10 \mathrm{pt}$, Complex Script Font: $10 \mathrm{pt}$

Formatted: Font: 10 pt, Complex Script Font: $10 \mathrm{pt}$

Formatted: Font: 10 pt, Complex Script Font: $10 \mathrm{pt}$

Formatted: Font: 10 pt, Complex Script Font: $10 \mathrm{pt}$

Formatted: Font: 10 pt, Complex Script Font: $10 \mathrm{pt}$

Formatted: Font: $10 \mathrm{pt}$, Complex

Script Font: $10 \mathrm{pt}$

Formatted: Font: $10 \mathrm{pt}$, Complex Script Font: 10 pt, Superscript

Formatted: Font: $10 \mathrm{pt}$, Complex Script Font: $10 \mathrm{pt}$

Formatted: Font: $10 \mathrm{pt}$, Complex Script Font: $10 \mathrm{pt}$

Formatted: Font: 10 pt, Complex Script Font: $10 \mathrm{pt}$

Formatted: Font: $10 \mathrm{pt}$, Complex Script Font: 10 pt, Superscript

Formatted

Deleted:

Formatted: Superscript

Formatted: Superscript

Deleted: $\mathscr{I}$

Deleted: ... [3] 


\begin{tabular}{|c|c|c|c|c|}
\hline \multirow[t]{3}{*}{ Cytokine (abbreviation) } & \multirow{3}{*}{$\begin{array}{l}\text { PDB filename } \\
\text { (monomer or } \\
\text { dimer) }\end{array}$} & \multirow{2}{*}{\multicolumn{2}{|c|}{$\begin{array}{l}\text { Intermolecular Interaction } \\
\text { Energies for } \\
\text { pentasaccharide ligands }\end{array}$}} & \multirow{3}{*}{$\begin{array}{l}\text { Position of heparin } \\
\text { binding site } \\
\end{array}$} \\
\hline & & & & \\
\hline & & \multirow{2}{*}{ Ido $\mathbf{A}_{-}^{1} \mathbf{C}_{4}$} & \multirow{2}{*}{$\underline{I d o A}_{-}^{2} \mathbf{S}_{\mathbf{0}}$} & \\
\hline Interleukin- $4 \frac{1}{-1}$ & 1hik.pdb (dimer) & & & $\begin{array}{l}\text { Helix C }(\mathrm{H} 74, \mathrm{~K} 77, \\
\underline{\mathrm{R} 81, \mathrm{~K} 84, \mathrm{R} 85, \mathrm{R} 88,}\end{array}$ \\
\hline Interleukin- $2 \frac{1}{\mathrm{~A}_{-}}$ & $\begin{array}{l}\text { 3ink.pdb } \\
\text { (monomer) }\end{array}$ & -1225 & -1252 & $\begin{array}{l}\mathrm{AB}(\mathrm{K} 32, \mathrm{~K} 35, \mathrm{R} 38) \\
\text { and } \mathrm{CD}(\mathrm{Q} 74, \mathrm{~K} 76, \\
\mathrm{R} 81) \text { loops }\end{array}$ \\
\hline Interleukin-13 & 1ijz.pdb (monomer) & -1099 & -1120 & $\begin{array}{l}\text { AB loop_(K25) and } \\
\text { Helix D (K97, K104, } \\
\text { K105, R108) }\end{array}$ \\
\hline Interleukin- $3_{\mathbf{x}_{-}}^{1}$ & 1jli.pdb (monomer) & -890 & -862 & $\begin{array}{l}\text { AB loop (K28, R29) } \\
\text { and Helix D (R108, } \\
\text { R109) }\end{array}$ \\
\hline Interleukin-5 $5_{-}^{1}$ & $\begin{array}{l}\text { 1hul.pdb } \\
\text { (intertwined dimer) }\end{array}$ & -1201 & -1215 & $\begin{array}{l}\text { Helix } \mathrm{C}(\mathrm{K} 70, \mathrm{~K} 77, \\
\mathrm{K} 84, \mathrm{~K} 85, \mathrm{R} 90) \text { and } \\
\text { N-terminus }\end{array}$ \\
\hline $\begin{array}{l}\text { Granulocyte-macrophage } \\
\text { colony stimulating factor } \\
\text { (GM-CSF) }\end{array}$ & $\begin{array}{l}1 \text { csg.pdb } \\
\text { (monomer) }\end{array}$ & -407 & -408 & \\
\hline Flt3 ligand & $\begin{array}{l}\text { 1 ete.pdb } \\
\text { (monomer) }\end{array}$ & -556 & -544 & \\
\hline Stem cell factor & $\begin{array}{l}\text { 1exz.pdb } \\
\text { (monomer) }\end{array}$ & -159 & -199 & \\
\hline
\end{tabular}

Formatted: Font: $10 \mathrm{pt}$, Complex Script Font: $10 \mathrm{pt}$

Formatted: Line spacing: 1.5 lines

Formatted: Font: $10 \mathrm{pt}$, Complex Script Font: $10 \mathrm{pt}$, Superscript

Formatted: Font: $10 \mathrm{pt}$, Complex Script Font: $10 \mathrm{pt}$

Formatted: Font: $10 \mathrm{pt}$, Complex Script Font: $10 \mathrm{pt}$

Formatted

Deleted: *

Formatted

Formatted

Formatted

Formatted

Formatted

Deleted:

Formatted

Formatted

Formatted

Formatted

Formatted

Deleted: Helix D and

Formatted

Formatted

Deleted: *

Formatted

Formatted

Deleted: Helix D

Deleted: and

Formatted

Formatted

Deleted:

Formatted

Formatted

Formatted

Formatted

Formatted

Deleted: e.pdb

Formatted

Formatted

Deleted:

Formatted: Superscript

Table 3: Prediction of heparin binding to the interferon/IL10 group of 4-helical cytokines.

\section{${ }_{2}^{1}$ Reported to interact with heparin: see text \\ ${ }^{2}$ Residues containing atoms within $3.5 \AA$ of ligand in the 5 lowest energy complexes}




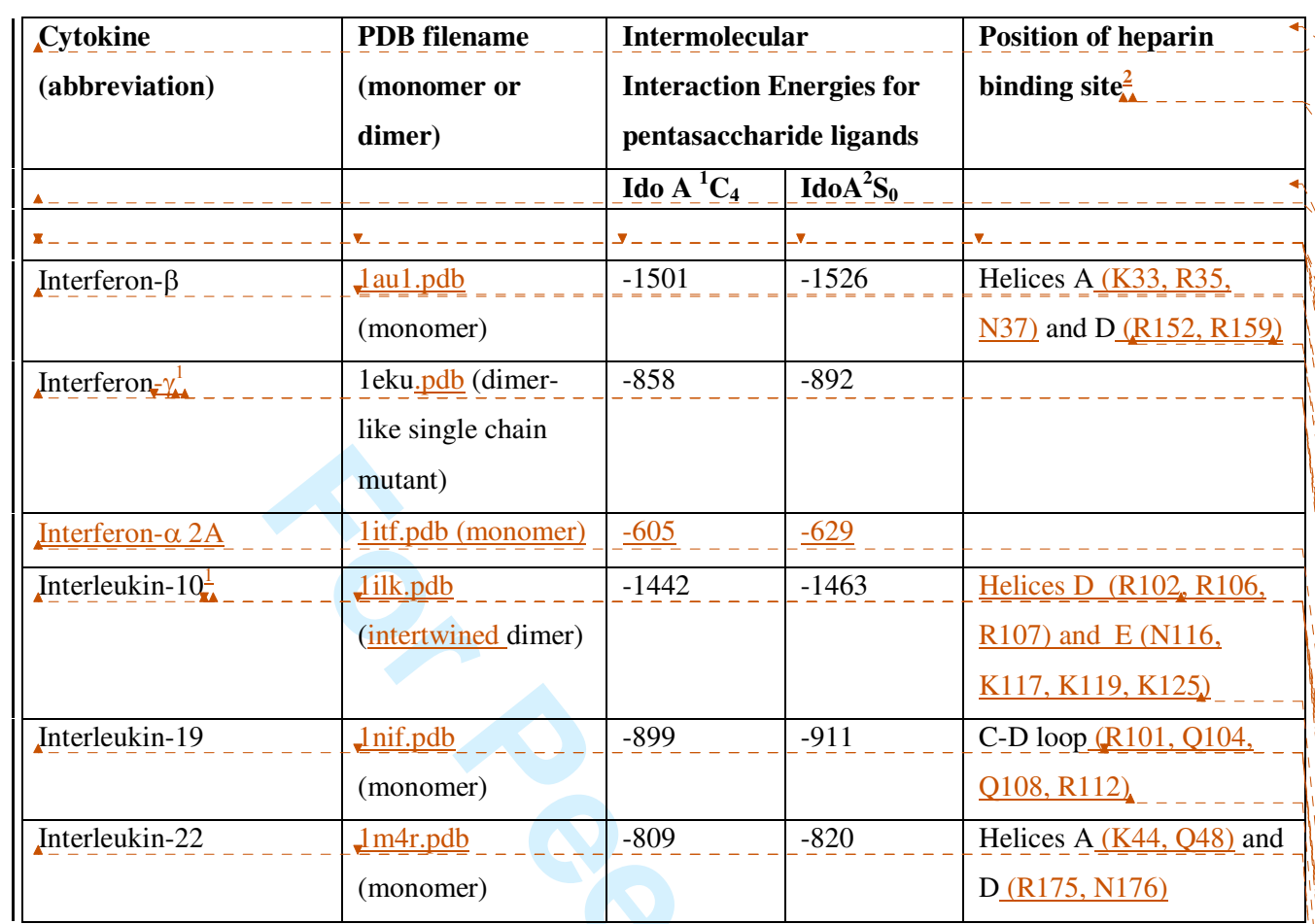

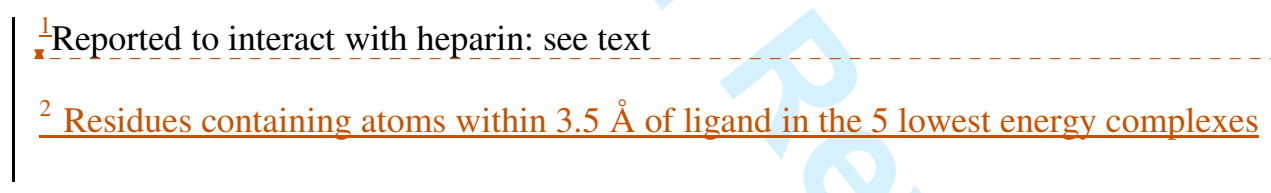

Formatted: Font: 10 pt, Complex Script Font: $10 \mathrm{pt}$

Formatted: Line spacing: 1.5 lines

Formatted: Font: $10 \mathrm{pt}$, Complex Script Font: 10 pt, Superscript

Formatted: Font: $10 \mathrm{pt}$, Complex Script Font: $10 \mathrm{pt}$

Formatted: Font: $10 \mathrm{pt}$, Complex Script Font: $10 \mathrm{pt}$

Formatted: Line spacing: Multiple $1.15 \mathrm{li}$

Deleted: Interferon- $\alpha 2 \mathrm{~A}$

Formatted: Font: 10 pt, Complex Script Font: $10 \mathrm{pt}$

Deleted: 1ITF (monomer)

Deleted: -605

Deleted: -629

Deleted: Helices A and D

Formatted: Font: $10 \mathrm{pt}$, Complex

Script Font: $10 \mathrm{pt}$

Deleted: 1AU1

Formatted: Font: 10 pt, Complex Script Font: $10 \mathrm{pt}$

Formatted: Font: 10 pt, Complex Script Font: $10 \mathrm{pt}$

\begin{tabular}{|l|}
\hline Formatted \\
\hline Deleted: $-\gamma *$ \\
\hline Formatted \\
\hline Formatted \\
\hline Formatted \\
\hline Formatted \\
\hline Deleted: ${ }^{*}$ \\
\hline Formatted \\
\hline Formatted \\
\hline Deleted: $1 \mathrm{ILK}$ \\
\hline Formatted \\
\hline Formatted \\
\hline Formatted \\
\hline Deleted: $1 \mathrm{NIF}$ \\
\hline Deleted: and C terminus \\
\hline Formatted \\
\hline Formatted \\
\hline Formatted \\
\hline Deleted: $1 \mathrm{M} 4 \mathrm{R}$ \\
\hline Deleted: ${ }^{*}$ \\
\hline Formatted: Superscript \\
\hline
\end{tabular}


Captions to the Figures

Fig. 1: the three disaccharides which make up the polysaccharide heparin. A) Alternating $\alpha$-D- $N$-acetyl glucosamine and $\beta$-D-glucuronic acid, the predominant disaccharide in heparan sulphate, forms long unsulfated domains ("N-regions"). The glucosamine in this disaccharide can sometimes be sulfated at C6. B) Alternating $\alpha$-D-glucosamine and $\alpha$-Liduronic acid; almost entirely N-sulfated, this is the most common disaccharide in heparin and forms the "S-regions" of heparan sulphate. In heparin, most of these disaccharides are also fully sulphated at $\mathrm{C} 2$ of iduronic acid and C6 of glucosamine. C) A sequence of non-acetylated $\alpha$-D-glucosamine and $\beta$-D-glucuronic acid, a combination found in the complex borders of S-regions. The glucosamine is almost always 2- $\mathrm{N}$ sulfated and may be 6-O-sulfated. Substitutions not shown in the figure, such as 2-Osulfate for glucuronic acid, or 3-O-sulfate for glucosamine, are also possible but rare. $\mathrm{N}$ acetyl glucosamine followed by iduronic acid does not occur in mammalian glucosaminoglycans.

Fig. 2: a detail from the crystal structure of FGF-1 complexed with a heparin hexasaccharide, with the protein shown in ribbon form and the saccharide in stick form. Two molecules of FGF-1 interact with the hexasaccharide, on opposite sides. Although the carbohydrate backbone is not symmetrical, the patterns of sulphate and carboxylate on either side are sufficiently similar as to bind to the same site on the protein.

Fig. 3: Ribbon diagrams showing structures of three proteins in the four helix bundle superfamily (reproduced from ref. 46 with permission). The four helices are labelled A, 
1

2

3

4

5

6

7

8

9

10
B, C and D by convention. Long loops between helices A and B, and helices C and D, run the length of the molecule, so that $\mathrm{A}$ and $\mathrm{B}$ run parallel, as do $\mathrm{C}$ and $\mathrm{D}$ in the opposite direction. A) a short-chain cytokine, showing a short two stranded beta sheet. B) a longchain cytokine, with a short extra helix after A and no beta stands. C) A member of the interferon/IL-10 family, with a helix in the C-D connection.

Fig. 4: The predicted heparin binding site for erythropoietin. EPO (the central bundle of helices, coloured red)) and its receptor (largely blue-coloured strands) are represented as a ribbon diagram, with the basic residues on EPO predicted to bind heparin displayed as sticks and coloured green. The potential heparin-binding site runs along helix D, and overlaps with the receptor binding site [35].

Fig. 5: Four short-chain cytokines predicted to bind heparin (Table 1). The structures of IL-2 (3ink.pdb; pale blue), IL-3 (1jli.pdb; yellow) IL-4 (1hik.pdb; purple) and IL-13 (1ijz.pdb; green) shown as superimposed ribbon diagrams (in a similar orientation to the structures in Fig. 3), each in complex with its lowest energy heparin pentasaccharide (Table 1). The four predicted heparin-binding sites do not overlap. 


\section{References}

1. L.P. Schacter, C. Anderson, R.M. Canetta, S. Kelley, C. Nicaise, N. Onetto, M. Rozencweig, L. Smaldone, B. Winograd. Drug Discovery and Development in the Pharmaceutical-Industry. Semin. Oncol., 19, 613 (1992).

2. D.L. Rabenstein. Heparin and heparan sulfate: structure and function. Nat Prod. $\operatorname{Rep}_{\text {. }}$ 19, 312 (2002).

3. E. Forsberg, G. Pejler, M. Ringvall, C. Lunderius, B. Tomasini-Johansson, M. Kusche-Gullberg, I. Eriksson, J. Ledin, L. Hellman, L. Kjellen. Abnormal mast cells in mice deficient in a heparin-synthesizing enzyme. Nature, 400, 773 (1999).

4. D.E. Humphries, G.W. Wong, D.S. Friend, M.F. Gurish, W.T. Qiu, C.F. Huang, A.H. Sharpe, R.L. Stevens. Heparin is essential for the storage of specific granule proteases in mast cells. Nature, 400, 769 (1999).

5. S.M. Knox, J.M. Whitelock. Perlecan: how does one molecule do so many things? Cell. Mol. Life Sci., 63, 2435 (2006).

6. C.R. Parish. The role of heparan sulphate in inflammation. Nat. Rev. Immunol., 6, 633 (2006).

7. A.I. de Agostini. An unexpected role for anticoagulant heparan sulfate proteoglycans in reproduction. Swiss Med ${ }_{\text {, }}$ Wkly, 136, 583 (2006).

\begin{tabular}{|l|}
\hline Deleted: $u r a l$ \\
\hline Deleted: $u c t$ \\
\hline Deleted: orts \\
\hline
\end{tabular}

S.M. Cool, V. Nurcombe. Heparan sulfate regulation of progenitor cell fate. $J$. Cell. Biochem., 99, 1040 (2006).

9. M. Petitou, C.A.A. van Boeckel. A synthetic antithrombin III binding pentasaccharide is now a drug! What comes next? Angew. Chem. Int. Edit., 43, 3118 (2004).

10. M. Mohammadi, S.K. Olsen, R. Goetz. A protein canyon in the FGF-FGF receptor dimer selects from an a la carte menu of heparan sulfate motifs. Curr. Opin. Struct. Biol., 15, 506 (2005).

11. J. Kreuger, D. Spillmann, J.P. Li, U. Lindahl. Interactions between heparan sulfate and proteins: the concept of specificity. J. Cell Biol., 174, 323 (2006).

12. J.D. Esko, S.B. Selleck. Order out of chaos: Assembly of ligand binding sites in heparan sulfate. Annu. Rev. Biochem., 71, 435 (2002). 
13. M.S.G. Pavao, P.A.S. Mourao, B. Mulloy, D.M. Tollefsen. A unique dermatan sulfate-like glycosaminoglycan from ascidian - Its structure and the effect of its unusual sulfation pattern on anticoagulant activity. J. Biol. Chem., 270, 31027 (1995).

14. A.P. Alves, B. Mulloy, J.A. Diniz, P.A.S. Mourao. Sulfated polysaccharides from the egg jelly layer are species-specific inducers of acrosomal reaction in sperms of sea urchins. J. Biol. Chem., 272, 6965 (1997).

15. B. Mulloy. The specificity of interactions between proteins and sulfated polysaccharides. Anais Acad. Bras. Cienc., 77, 651 (2005).

16. D.J. Stauber, A.D. DiGabriele, W.A. Hendrickson. Structural interactions of fibroblast growth factor receptor with its ligands. Proc. Natl. Acad. Sci. U. S. A, 97, 49 (2000).

17. O. Ostrovsky, B. Berman, J. Gallagher, B. Mulloy, D.G. Fernig, M. Delehedde, D. Ron. Differential effects of heparin saccharides on the formation of specific fibroblast growth factor (FGF) and FGF receptor complexes. J. Biol. Chem., 277, 2444 (2002).

18. P. Gund, J.D. Andose, J.B. Rhodes, G.M. Smith. Three-dimensional molecular modeling and drug design. Science, 208, 1425 (1980).

19. H. Verli, J. A. Guimaraes. Insights into the induced fit mechanism in antithrombin-heparin interaction using molecular dynamics simulations. J. Mol. Graph. Model., 24, 203 (2005).

20. W. Bitomsky, R.C. Wade. Docking of Glycosaminoglycans to Heparin-Binding Proteins: Validation for aFGF, bFGF, and Antithrombin and Application to IL-8. J. Am. Chem. Soc., 121, 3004 (1999).

21. S. Ricard-Blum, O. Feraud, H. Lortat-Jacob, A. Rencurosi, N. Fukai, F. Dkhissi, D. Vittet, A. Imberty, B.R. Olsen, M. van der Rest. Characterization of endostatin binding to heparin and heparan sulfate by surface plasmon resonance and molecular modeling - Role of divalent cations. J. Biol. Chem., 279, 2927 (2004).

22. E. Krieger, E. Geretti, B. Brandner, B. Goger, T.N. Wells, A J. Kungl. A structural and dynamic model for the interaction of interleukin-8 and glycosaminoglycans: Support from isothermal fluorescence titrations. Proteins, 54, 768 (2004).

23. Sachchidanand, O. Lequin, D. Staunton, B. Mulloy, M.J. Forster, K. Yoshida, I. D. Campbell. Mapping the heparin-binding site on the (13-14)F3 fragment of fibronectin. J. Biol. Chem., 277, 50629 (2002). 
24. S.E. Stringer, M.J. Forster, B. Mulloy, C.R. Bishop, G.J. Graham, J.T. Gallagher. Characterization of the binding site on heparan sulfate for macrophage inflammatory protein 1 alpha. Blood, 100, 1543 (2002).

25. D.J. Mahoney, B. Mulloy, M.J. Forster, C.D. Blundell, E. Fries, C.M. Milner, A.J. Day. Characterization of the interaction between tumor necrosis factor-stimulated gene-6 and heparin - Implications for the inhibition of plasmin in extracellular matrix microenvironments. J. Biol. Chem., 280, 27044 (2005).

26. M.J. Forster, B. Mulloy. Computational approaches to the identification of heparin-binding sites on the surfaces of proteins. Biochem. Soc. Trans., 34, 431 (2006).

27. G.M. Morris, D.S. Goodsell, R. Huey, A.J. Olson. Distributed automated docking of flexible ligands to proteins: parallel applications of AutoDock 2.4. J. Comput. Aided Mol. Des, 10, 293 (1996).

28. B. Mulloy, M.J. Forster, C. Jones, D.B. Davies. N.m.r. and molecular-modelling studies of the solution conformation of heparin. Biochem. J., 293, 849 (1993).

29. B. Mulloy, M.J. Forster. Conformation and dynamics of heparin and heparan sulfate. Glycobiology, 10, 1147 (2000).

30. A. Imberty, H. Lortat-Jacob, S. Perez. Structural view of glycosaminoglycanprotein interactions. Carbohydr. Res., 342, 430 (2007).

31. A.G. Murzin, S.E. Brenner, T. Hubbard, C. Chothia. SCOP - A Structural Classification of Proteins Database for the Investigation of Sequences and Structures. J. Mol. Biol., 247, 536 (1995).

32. C. Yoon, S.C. Johnston, J. Tang, M. Stahl, J.F. Tobin, W.S. Somers. Charged residues dominate a unique interlocking topography in the heterodimeric cytokine interleukin-12. EMBO J., 19, 3530 (2000).

33. R.S. Mummery, C.C. Rider. Characterization of the heparin-binding properties of IL-6. Journal of Immunology, 165, 5671 (2000).

34. W. He, K. Gong, D.K. Smith, N.Y. Ip. The N-terminal cytokine binding domain of LIFR is required for CNTF binding and signaling. FEBS Lett., 579, 4317 (2005).

35. R.S. Syed, S.W. Reid, C.W. Li, J. C. Cheetham, K.H. Aoki, B.S. Liu, H.J. Zhan, T.D. Osslund, A J. Chirino, J D. Zhang, J. Finer-Moore, S. Elliott, K. Sitney, B.A. Katz, D.J. Matthews, J.J. Wendoloski, J. Egrie, R.M. Stroud. Efficiency of signalling through cytokine receptors depends critically on receptor orientation. Nature, 395, 511 (1998). 
36. A.Y. Liang, Y.P. Chao, X.J. Liu, Y.G. Du, K.Y. Wang, S.J. Qian, B.C. Lin. Separation, identification, and interaction of heparin oligosaccharides with granulocyte-colony stimulating factor using capillary electrophoresis and mass spectrometry. Electrophoresis, 26, 3460 (2005).

37. C. Zamiri, M.J. Groves. Stabilization of somatropin by heparin. J. Pharm. Pharmacol., 57, 555 (2005).

38. S. Najjam, B. Mulloy, J. Theze, M. Gordon, R. Gibbs, C.C. Rider. Further characterization of the binding of human recombinant interleukin 2 to heparin and identification of putative binding sites. Glycobiology, 8, 509 (1998).

39. R. Roberts, J. Gallagher, E. Spooncer, T.D. Allen, F. Bloomfield, T.M. Dexter. Heparan sulphate bound growth factors: a mechanism for stromal cell mediated haemopoiesis. Nature, 332, 376 (1988).

40. H. Lortat-Jacob, P. Garrone, J. Banchereau, J.A. Grimaud. Human interleukin 4 is a glycosaminoglycan-binding protein. Cytokine, 9, 101 (1997).

41. R.J. Lipscombe, A.M. Nakhoul, C.J. Sanderson, D.R. Coombe. Interleukin-5 binds to heparin heparan sulfate. A model for an interaction with extracellular matrix. J. Leuk. Biol., 63, 342 (1998).

42. A. Sebollela, T.C. Cagliari, G.S.C.S. Limaverde, A. Chapeaurouge, M.H.F. Sorgine, T. Coelho-Sampaio, C.H.I. Ramos, S.T. Ferreira. Heparin-binding sites in granulocyte-macrophage colony-stimulating factor - Localization and regulation by histidine ionization. J. Biol. Chem., 280, 31949 (2005).

43. S.N. Savvides, T. Boone, P.A. Karplus. Flt3 ligand structure and unexpected commonalities of helical bundles and cystine knots. Nat. Struct. Biol., 7, 486 (2000).

44. H. Lortat-Jacob, J.A. Grimaud. Interferon-gamma binds to heparan sulfate by a cluster of amino acids located in the C-terminal part of the molecule. FEBS Lett., 280, 152 (1991).

45. S. Salek-Ardakani, J.R. Arrand, D. Shaw, M. Mackett. Heparin and heparan sulfate bind interleukin-10 and modulate its activity. Blood, 96, 1879 (2000).

46. D.A. Rozwarski, A.M. Gronenborn, G.M. Clore, J.F. Bazan, A. Bohm, A. Wlodawer, M. Hatada, P.A. Karplus. Structural Comparisons Among the ShortChain Helical Cytokines. Structure, 2, 159 (1994).

47. M.O. Huising, C.P. Kruiswijk, G. Flik. Phylogeny and evolution of class-I helical cytokines. J. Endocrinol., 189, 1 (2006).

48. B. Mulloy, R.J. Linhardt. Order out of complexity - protein structures that interact with heparin. Curr. Opin. Struct. Biol., 11, 623 (2001). 
2

Formatted: Indent: Before: $0 \mathrm{pt}$, 
Font: 10 pt, Complex Script Font: 10 pt

Page 17: [2] Formatted NIBSC 10/29/2007 3:16:00 PM

Font: 10 pt, Complex Script Font: 10 pt

Line spacing: Multiple 1.15 li

Page 18: [5] Formatted

NIBSC

10/29/2007 3:16:00 PM

Font: 10 pt, Complex Script Font: 10 pt

Page 18: [6] Formatted

NIBSC

10/29/2007 3:16:00 PM

Font: 10 pt, Complex Script Font: 10 pt, Superscript

Page 18: [7] Formatted

NIBSC

10/29/2007 3:16:00 PM

Font: $10 \mathrm{pt}$, Complex Script Font: $10 \mathrm{pt}$

Page 18: [8] Formatted
Font: $10 \mathrm{pt}$, Complex Script Font: $10 \mathrm{pt}$
NIBSC 10/29/2007 3:16:00 PM

Page 18: [9] Formatted

Font: 10 pt, Complex Script Font: 10 pt

Page 18: [10] Formatted

Font: 10 pt, Complex Script Font: 10 pt, Superscript
Page 18: [11] Formatted NIBSC

Font: 10 pt, Complex Script Font: $10 \mathrm{pt}$

Page 18: [12] Formatted

Font: 10 pt, Complex Script Font: 10 pt

Page 18: [13] Formatted

Font: 10 pt, Complex Script Font: 10 pt

Page 18: [14] Formatted

Font: 10 pt, Complex Script Font: 10 pt

Page 18: [15] Formatted

Font: $10 \mathrm{pt}$, Complex Script Font: $10 \mathrm{pt}$

Page 18: [16] Formatted

Font: 10 pt, Complex Script Font: 10 pt

NIBSC

NIBSC

NIBSC

NIBSC

NIBSC
NIBSC

NIBSC

10/29/2007 3:16:00 PM

10/29/2007 3:16:00 PM

10/29/2007 3:16:00 PM

10/29/2007 3:16:00 PM

10/29/2007 3:16:00 PM

10/29/2007 3:16:00 PM

10/29/2007 3:16:00 PM

10/29/2007 3:16:00 PM

Page 18: [17] Formatted

NIBSC

10/29/2007 3:16:00 PM

Font: 10 pt, Complex Script Font: 10 pt, Superscript

Page 18: [18] Formatted

NIBSC

10/29/2007 3:16:00 PM

Font: 10 pt, Complex Script Font: 10 pt

Page 18: [19] Formatted NIBSC

10/29/2007 3:16:00 PM

Font: 10 pt, Complex Script Font: 10 pt 
Page 18: [20] Formatted NIBSC

10/29/2007 3:16:00 PM

Font: 10 pt, Complex Script Font: 10 pt

Page 18: [21] Formatted NIBSC

10/29/2007 3:16:00 PM

Font: 10 pt, Complex Script Font: 10 pt, Superscript

Page 18: [22] Formatted NIBSC

10/29/2007 3:16:00 PM

Font: 10 pt, Complex Script Font: 10 pt

Page 18: [23] Formatted
Font: $10 \mathrm{pt}$, Complex Script Font: $10 \mathrm{pt}$

Page 18: [24] Formatted

NIBSC

10/29/2007 3:16:00 PM

Font: 10 pt, Complex Script Font: 10 pt

Page 18: [25] Formatted

NIBSC

10/29/2007 3:16:00 PM

Font: 10 pt, Complex Script Font: 10 pt

Page 18: [26] Formatted

NIBSC

10/29/2007 3:16:00 PM

Font: 10 pt, Complex Script Font: 10 pt

\begin{tabular}{|l|l|}
\hline Page 18: [27] Deleted & \\
\hline
\end{tabular}

Page 18: [28] Formatted

NIBSC

10/29/2007 3:16:00 PM

Font: $11 \mathrm{pt}$, Complex Script Font: $11 \mathrm{pt}$

Page 19: [29] Formatted

NIBSC

10/24/2007 5:34:00 PM

Font: 10 pt, Complex Script Font: 10 pt

Page 19: [30] Formatted

NIBSC

10/29/2007 3:16:00 PM

Font: 10 pt, Complex Script Font: 10 pt, Superscript

Page 19: [31] Formatted

NIBSC

10/29/2007 3:16:00 PM

Font: $10 \mathrm{pt}$, Complex Script Font: $10 \mathrm{pt}$

Page 19: [32] Formatted

NIBSC

10/29/2007 3:16:00 PM

Font: 10 pt, Complex Script Font: 10 pt

Page 19: [33] Formatted

NIBSC

10/29/2007 3:16:00 PM

Font: $10 \mathrm{pt}$, Complex Script Font: $10 \mathrm{pt}$

Page 19: [34] Formatted

NIBSC

10/29/2007 3:16:00 PM

Font: 10 pt, Complex Script Font: 10 pt, Superscript

Page 19: [35] Formatted

NIBSC

10/29/2007 3:16:00 PM

Font: 10 pt, Complex Script Font: 10 pt

Page 19: [36] Formatted

NIBSC

10/29/2007 3:16:00 PM

Font: 10 pt, Complex Script Font: 10 pt

Page 19: [37] Formatted

NIBSC

10/29/2007 3:16:00 PM

Font: 10 pt, Complex Script Font: 10 pt

Page 19: [38] Formatted

NIBSC

10/29/2007 3:16:00 PM

Font: 10 pt, Complex Script Font: 10 pt

Page 19: [39] Formatted

NIBSC

10/29/2007 3:16:00 PM

Font: 10 pt, Complex Script Font: 10 pt 
1

2

3

4

5

6

7

8

9

10

11

12

13

14

15

16

17

18

19

20

21

22

23

24

25

26

27

28

29

30

31

32

33

34

35

36

37

38

39

40

41

42

43

44

45

46

47

48

49

50

51

52

53

54

55

56

57

58

59

60
Font: 10 pt, Complex Script Font: 10 pt

Page 19: [41] Formatted

NIBSC

10/29/2007 3:16:00 PM
Font: 10 pt, Complex Script Font: 10 pt 


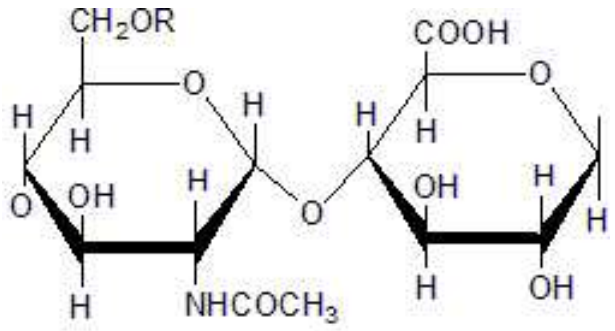

$-4 \mathrm{Gl}$ cNAc $\alpha 1-4 \mathrm{GlcA} \beta 1-$

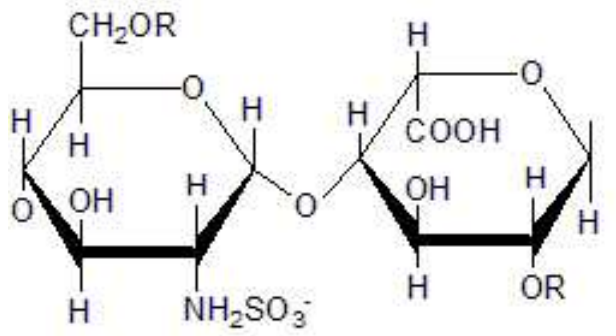

$-4 \mathrm{Glc}\left(\mathrm{NSO}_{3}{ }^{-}\right) \alpha 1-4 \mathrm{IdoA} \alpha 1-$

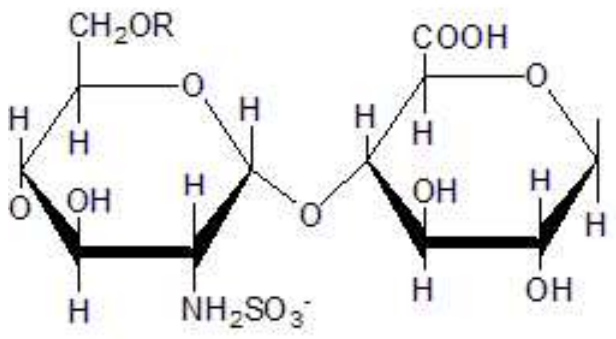

$-4 \mathrm{Glc}\left(\mathrm{NSO}_{3}{ }^{-}\right) \alpha 1-4 \mathrm{GlcA} \beta 1-$

$$
\mathrm{R}=\mathrm{H} \text { or } \mathrm{SO}_{3}^{-}
$$

Fig. 1: the three disaccharides which make up the polysaccharide heparin. A) Alternating $\alpha-D-N-$ acetyl glucosamine and $\beta$-D-glucuronic acid, the predominant disaccharide in heparan sulphate, forms long unsulfated domains (Â円 N-regionsÂ $\square$ ). The glucosamine in this disaccharide can sometimes be sulfated at C6. B) Alternating $\alpha$-D-glucosamine and $\alpha$-L-iduronic acid; almost entirely $\mathrm{N}$-sulfated, this is the most common disaccharide in heparin and forms the Ẫ S-regionsÂn of heparan sulphate. In heparin, most of these disaccharides are also fully sulphated at C2 of iduronic acid and C 6 of glucosamine. C) A sequence of non-acetylated $\alpha$-D-glucosamine and $\beta$-D-glucuronic acid, a combination found in the complex borders of S-regions. The glucosamine is almost always 2$\mathrm{N}$-sulfated and may be 6-O-sulfated. Substitutions not shown in the figure, such as 2-O-sulfate for glucuronic acid, or 3-O-sulfate for glucosamine, are also possible but rare. $\mathrm{N}$-acetyl glucosamine followed by iduronic acid does not occur in mammalian glucosaminoglycans. $89 \times 228 \mathrm{~mm}(72 \times 72 \mathrm{DPI})$ 
Fig. 2: a detail from the crystal structure of FGF-1 complexed with a heparin hexasaccharide, with the protein shown in ribbon form and the saccharide in stick form. Two molecules of FGF-1 interact with the hexasaccharide, on opposite sides. Although the carbohydrate backbone is not symmetrical, the patterns of sulphate and carboxylate on either side are sufficiently similar as to bind to the same site on the protein. 

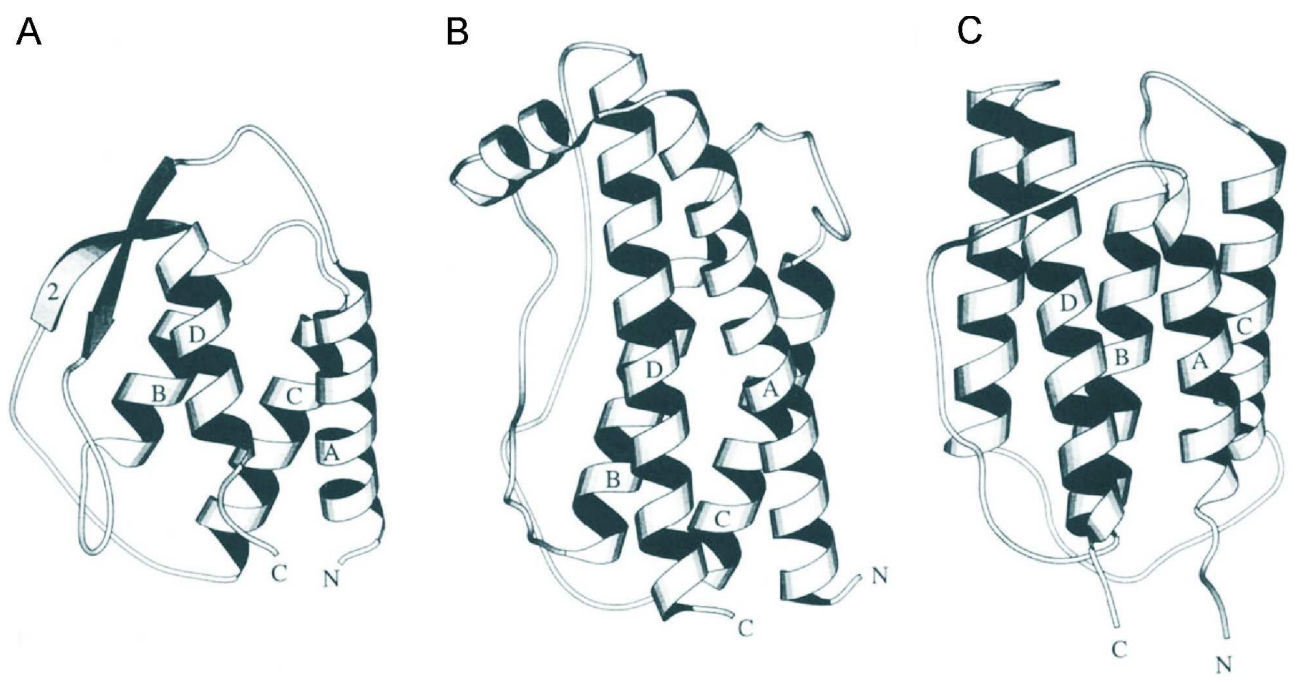

Fig. 3: Ribbon diagrams showing structures of three proteins in the four helix bundle superfamily (reproduced from ref. 33 with permission). The four helices are labelled A, B, C and D by convention. Long loops between helices $A$ and $B$, and helices $C$ and $D$, run the length of the molecule, so that $A$ and $B$ run parallel, as do $C$ and $D$ in the opposite direction. A) a short-chain cytokine, showing a short two stranded beta sheet. B) a long-chain cytokine, with a short extra helix after A and no beta stands. C) A member of the interferon/IL-10 family, with a helix in the C-D connection.

$169 \times 86 \mathrm{~mm}(300 \times 300 \mathrm{DPI})$ 
Fig. 4: The predicted heparin binding site for erythropoietin. EPO (the central bundle of helices, coloured red)) and its receptor (largely blue-coloured strands) are represented as a ribbon diagram, with the basic residues on EPO predicted to bind heparin displayed as sticks and coloured green. The potential heparin-binding site runs along helix $D$, and overlaps with the receptor binding site (31).

$317 \times 240 \mathrm{~mm}(72 \times 72 \mathrm{DPI})$ 
Fig. 5: Four short-chain cytokines predicted to bind heparin (Table 1). The structures of IL-2 (3ink.pdb; pale blue), IL-3 (1jli.pdb; yellow) IL-4 (1hik.pdb; purple) and IL-13 (1ijz.pdb; green) shown as superimposed ribbon diagrams (in a similar orientation to the structures in Fig. 3), each in complex with its lowest energy heparin pentasaccharide (Table 1 ). The four predicted heparinbinding sites do not overlap. $138 \times 154 \mathrm{~mm}(300 \times 300 \mathrm{DPI})$ 